\title{
UV light blocks EGFR signalling in human cancer cell lines
}

\author{
B.B. OLSEN ${ }^{1 *}$, M.T. NEVES-PETERSEN ${ }^{2 *}$, S. KLITGAARD ${ }^{2}$, O.G. ISSINGER ${ }^{1}$ and S.B. PETERSEN ${ }^{2}$ \\ ${ }^{1}$ Institute for Biochemistry and Molecular Biology, University of Southern Denmark, Campusvej 55, \\ 5230 Odense M; ${ }^{2}$ NanoBiotechnology Group, Department of Physics and Nanotechnology, \\ Aalborg University, Skjernvej 4A, 9220 Aalborg Ø, Denmark
}

Received July 26, 2006; Accepted September 7, 2006

\begin{abstract}
UV light excites aromatic residues, causing these to disrupt nearby disulphide bridges. The EGF receptor is rich in aromatic residues near the disulphide bridges. Herein we show that laser-pulsed UV illumination of two different skin-derived cancer cell lines i.e. Cal-39 and A431, which both overexpress the EGF receptor, leads to arrest of the EGFR signaling pathway. The phosphorylation status of the receptor and the level of phosphorylated downstream signaling molecules i.e. AKT and the mitogen activated protein kinases (MAPKs) ERK1 and 2 is detected by Western blotting using phosphospecific antibodies. There was a threshold level, below which the receptor could not be blocked. In addition, illumination caused the cells to upregulate the cyclindependent kinase inhibitor $\mathrm{p} 21^{\mathrm{WAF} 1}$, irrespective of the $\mathrm{p} 53$ status. Since the EGF receptor is often overexpressed in cancers and other proliferative skin disorders, it might be possible to significantly reduce the proliferative potential of these cells making them good targets for laser-pulsed UV light treatment.
\end{abstract}

\section{Introduction}

The epidermal growth factor receptor (EGFR), also known as HER1/Erb-B1 belongs to the ErbB family of receptor tyrosine kinases (RTKs) $(1,2)$. Binding of ligands such as EGF and TGF, leads to homo- and heterodimerization of the receptors (3). Dimerization in the case of EGFR leads to autophosphorylation of specific tyrosine residues in the intracellular tyrosine kinase domain. These phosphorylated tyrosine residues serve as docking sites for other kinases e.g.

Correspondence to: Professor Steffen B. Petersen, NanoBiotechnology Group, Department of Physics and Nanotechnology, Aalborg University, Skjernvej 4A, 9220 Aalborg Ø, Denmark

E-mail: sp@nanobio.aau.dk

${ }^{*}$ Contributed equally

Key words: UV light, EGF receptor, signalling, apoptosis, cancer, therapy phosphatidylinositol-3-kinase (PI3K) and adaptor proteins e.g. Shc and Grb2. This in turn initiates cascades of intracellular signaling pathways including the PI3K-AKT pathway and the Ras-Raf-MAPK pathway $(2,3)$. Activation of the ErB receptor family triggers a number of different responses including mitogenesis, apoptosis, cellular motility, angiogenesis and differentiation (2). Activation of the MAPK and PI3K/ AKT signaling pathways leads to the expression of mitogenic factors, which can induce the malignant conversion of keratinocytes, tumor progression and invasive potential (4-9). This is supported by the finding that the EGF receptor is overexpressed or subject to uncontrolled signaling in a number of solid tumors (10-21) and is often associated with poor prognosis and advanced disease. The current strategy in targeting the ErbB receptors includes monoclonal antibodies and small-molecule kinase inhibitors, which inhibit autophosphorylation and downstream signaling (22).

The spatial proximity between aromatic residues and disulphide bridges in proteins has been preserved during molecular evolution $(23,24)$. UV illumination of aromatic residues in proteins leads to the disruption of nearby disulphide bridges, leading to free reactive thiol groups, radicals and ions (25-28, Neves-Petersen et al, unpublished data). Interestingly, the EGF receptor is rich in these amino acids known to be involved in photophysical and photochemical reactions triggered by UV light.

Herein we show that LP-UV treatment of two skinderived tumor cell lines, i.e. A431 and Cal-39 leads to the inhibition of the EGF receptor and key downstream molecules such as AKT1 and ERK1/2 involved in the RTKcatalyzed signaling cascade. Our results show a potential for treatment of skin diseases associated with increased proliferation relating to the EGF receptor e.g. warts (29), condylomas $(30,31)$, psoriasis $(32,33)$ and skin cancer.

\section{Materials and methods}

Cell culture. A431 cells (human epidermoid carcinoma cells) were maintained in RPMI medium (Gibco BRL) supplemented with 10\% fetal bovine serum (Bio Whittaker Europe). Cal-39 cells (human vulva squamous cell carcinoma cells) were maintained in DMEM medium (Gibco BRL) supplemented with $20 \%$ fetal bovine serum, $0.5 \mathrm{nM}$ hydrocortisone (Clonetics) and $0.01 \mu \mathrm{g} / \mathrm{ml}$ EGF (Calbiochem). Both cell 
lines were obtained from DSMZ, Braunschweig, Germany and kept at $37^{\circ} \mathrm{C}$ in a humidified atmosphere and $5 \% \mathrm{CO}_{2}$. For the experiments, $80-85 \%$ confluent cells were serumstarved for $18 \mathrm{~h}$ prior to light illumination.

Illumination. Illumination was carried out with femtosecond lasting laser pulses at $280 \mathrm{~nm}$. The pulses were generated by sending the output from a Spectra Physics Tsunami laser (<100fs pulse duration, $12 \mathrm{~nm}$ FWHM, $80 \mathrm{MHz}$ repetition rate, $\lambda=840 \mathrm{~nm}$, Tsunami 3960, Spectra Physics, Mountain View, CA pumped by a high power ( $5 \mathrm{~W}$ at $532 \mathrm{~nm}$ ) solid state laser Millennia V, Spectra Physics) through a pulse picker, which decreased the pulse repetition rate to $8 \mathrm{MHz}$. The fundamental pulse was mixed with its second harmonic $(420 \mathrm{~nm})$ in a frequency doubler/tripler (GWU; Spectra Physics) to generate a pulse at $280 \mathrm{~nm}$. The power of the $280 \mathrm{~nm}$ light after GWU was $0.273 \mathrm{~mW}$. The pulse was expanded prior to sample illumination with a diffusive lens in order to illuminate as large an area as possible (half a petri dish, $\mathrm{d}=35 \mathrm{~mm}$ ). Each halfplate was illuminated at the indicated times. For activation of the EGFR pathway the cells were incubated with $100 \mathrm{ng} / \mathrm{ml} \mathrm{EGF}$ (Calbiochem) for $5 \mathrm{~min}$ at $37^{\circ} \mathrm{C}$ either prior to or after illumination.

Protein extraction and Western blotting. Cells were washed once in ice-cold PBS and scraped in $50 \mu 1$ lysis buffer [50 mM Tris- $\mathrm{HCl}$ pH 8.5, $150 \mathrm{mM} \mathrm{NaCl}, 1 \%$ Triton $\mathrm{X}-100,10 \%$ glycerol, $1 \mathrm{mM}$ DTT, $30 \mathrm{mM} \mathrm{NaPP}, 10 \mathrm{mM} \mathrm{NaF}, 1 \mathrm{mM}$ $\mathrm{Na}_{3} \mathrm{VO}_{4}, 100 \mathrm{nM}$ okadaic acid, Complete protease inhibitors (Roche)]. Lysates were incubated on ice for $15 \mathrm{~min}$ and cleared by centrifugation $\left(4^{\circ} \mathrm{C}, 12000 \mathrm{x} \mathrm{g}, 30 \mathrm{~min}\right)$. The supernantant was used for protein determination (34). Protein $(75 \mu \mathrm{g})$ was separated by $10 \%$ SDS-PAGE and the proteins transferred to a PVDF membrane (Bio-Rad) by wetblotting in $25 \mathrm{mM}$ Tris, $192 \mathrm{mM}$ glycine, $0.1 \%$ SDS, $20 \% \mathrm{MeOH}$. The membrane was blocked in blocking buffer $(0.2 \%$ casein, $0.1 \%$ Tween-20 in PBS) for $1 \mathrm{~h}$ and incubated with either monoclonal anti-AKT (BD Transduction Laboratories), antiPARP (Pharmingen), anti-ß-actin (Sigma) or polyclonal antiPhospho-AKT (T308) (Cell Signaling), anti-ERK1/2 (p42/p44) (Cell Signaling), anti-Phospho-ERK1/2 (P-p42/p44 (Thr202/Tyr204) (Cell Signaling), anti-EGFR (Santa Cruz), anti-Phospho-EGFR (Tyr1173) (Santa Cruz). After washing in blocking buffer the membranes were incubated with either a secondary goat anti-mouse antibody, goat anti-rabbit or sheep anti-goat coupled to alkaline phosphatase (Jackson immunoresearch laboratories) for $1 \mathrm{~h}$. Visualization was done with CDP-star (Tropix) according to the manufacturer's instructions.

\section{Results}

Laser-pulsed UV illumination blocks EGF receptor signaling above a certain power/threshold level in A431 cells. The human skin cancer cell line A431, which overexpress the EGF receptor [ $>1.5$ million receptors per cell (35)] was used to investigate whether laser-pulsed UV illumination could block EGF receptor signaling. Interestingly, the EGF receptor contains aromatic residues in close proximity to $\mathrm{S}-\mathrm{S}$ bridges making it a likely candidate for light-induced immobilization.

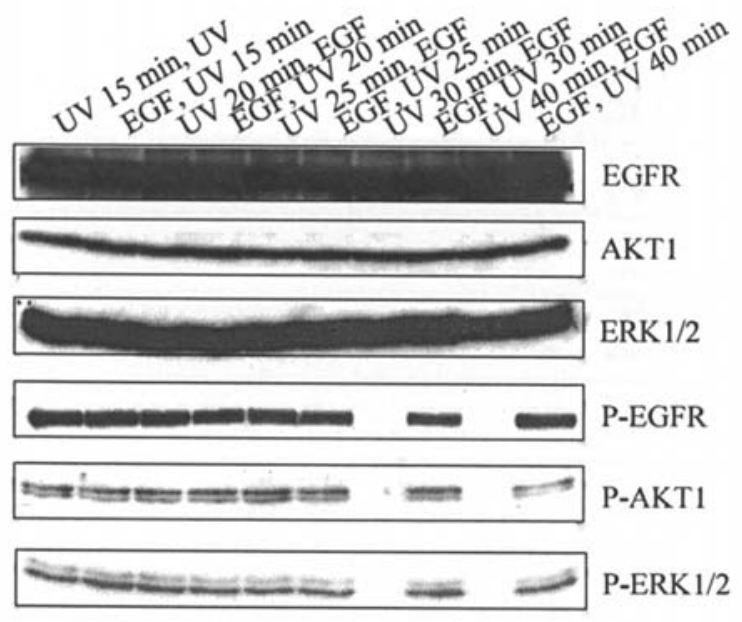

Figure 1. Laser-pulsed UV illumination of A431 cells blocks EGF receptor signaling. Cells were serum-starved and either treated for 5 min with $100 \mathrm{ng} / \mathrm{ml}$ EGF prior to or after illumination for the indicated time periods. Cell lysates $(75 \mu \mathrm{g})$ were separated by SDS-PAGE and the membrane probed with phospho-specific antibodies against the EGF receptor (P-Tyr1173), AKT (P-Thr308) or ERK1/2 (P-Thr202/P-Tyr204). In addition the membranes were probed with antibodies against total EGFR, AKT and ERK1/2 protein.

To assess the time required to inactivate the EGF receptor with UV light, a time course experiment was performed in A431 cells (Fig. 1). Cells were serum-starved prior to treatment and the cells were either illuminated at different time-points and then incubated with EGF or first treated with EGF followed by different UV light illumination times. The blockage in EGF receptor signaling was detected by Western blotting using phospho-specific antibodies against the EGFR receptor and the downstream signaling molecules AKT1 and ERK1/2. As seen in Fig. 1, there exists a power/threshold level above which it is possible to inactivate the EGF receptor, as seen by no phosphorylation of the EGF receptor and the downstream signaling molecules AKT and ERK1 and 2 (lanes 7-10), whereas below this threshold (lanes 1-6) no inactivation could be detected by Western blotting. Detection of total EGFR, AKT1 and ERK1/2 protein was used to ensure equal loading. The results show that illumination times for more than 30 min attenuate the EGFR signaling pathways.

Laser-pulsed UV immobilization also blocks EGF receptor signaling in Cal-39 cells. To see if the observed blockage of EGFR signaling in A431 cells also is found in other cell lines, illumination experiments were performed in another human skin cancer cell line, i.e. Cal-39, which expresses lower levels of the EGF receptor (Fig. 2 left and right part). Again Western blot detection of phosphorylated EGFR, AKT1 and ERK1/2 was used to assess the effect of the UV illumination.

Fig. 2 left part shows the results from the human squamous cell line A431. The cells were serum-starved prior to incubation with EGF and illumination. As expected, serum-starved cells (lane 1; control) showed no phosphorylation of either EGFR, AKT1 or ERK1/2, whereas incubation of cells with EGF led to activation of the EGFR signaling cascade assessed by phosphorylation of both the EGF receptor, and the two downstream effectors AKT and ERK1/2 (lane 2; EGF). EGF 


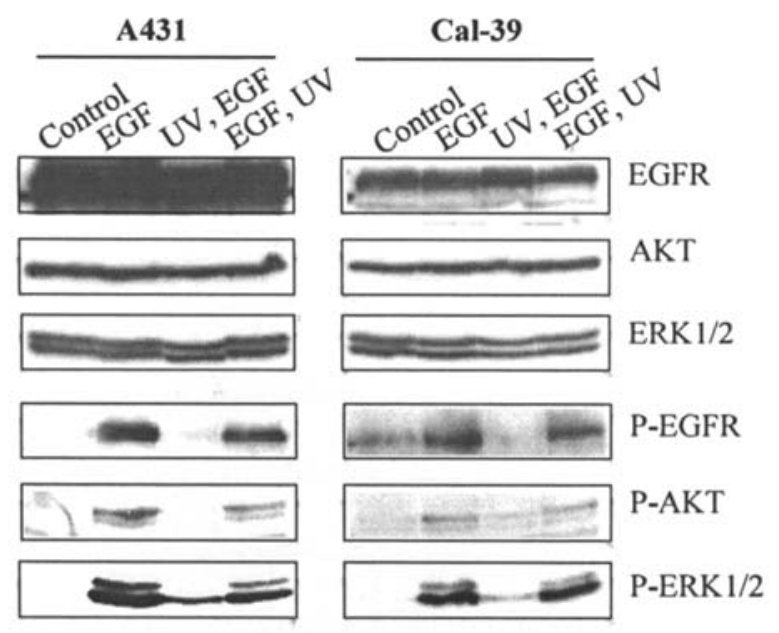

Figure 2. Laser-pulsed UV illumination blocks EGF receptor signaling in Cal-39 cells. Cal-39 and A431 cells were serum-starved and either treated for $5 \mathrm{~min}$ with $100 \mathrm{ng} / \mathrm{ml}$ EGF prior to or after illumination for $30 \mathrm{~min}$. As a control, lysates from serum-starved cells or cells treated with only EGF were loaded. Cell lysates $(75 \mu \mathrm{g})$ were separated by SDS-PAGE and the membrane probed with the antibodies described in Fig. 1

incubation prior to illumination did not change its ability to activate the phosphorylation cascade (lane 4; EGF, UV), whereas UV illumination prior to EGF treatment prevented activation of the EGFR, AKT1 and ERK1/2 (lane 4; UV, EGF), hence there is no effect of EGF once the cells have been illuminated. Western blot detection of total EGFR, AKT and ERK1/2 proteins show that the protein level is not affected by illumination.

The results using Cal-39 cells were the same (Fig. 2 right part) as for A431 cells. Illumination prior to EGF incubation prevented activation of the EGFR signaling cascade, whereas illumination after incubation with EGF had no effect on the activation of the signaling pathway. These results support the hypothesis that laser-pulsed UV can impact the EGF receptor and prevents its activation by ligand binding.

Laser-pulsed UV illumination upregulates p21 WAFI irrespective of the p53 status. Treatment of cells with monoclonal antibodies against the EGF receptor or tyrosine kinase inhibitors have been shown to upregulate the cyclin-dependent kinase inhibitor, p21 WAF1 $(36-40)$.

To test if $\mathrm{p} 21^{\mathrm{WAF} 1}$ was upregulated in response to laserpulsed UV illumination, both serum-starved Cal-39 and A431 cells were illuminated and returned to full medium and incubated for $24 \mathrm{~h}$. The levels of p21 ${ }^{\mathrm{WAF} 1}$ in illuminated cells in comparison to not illuminated cells were detected by Western blotting using an anti-p21 ${ }^{\mathrm{WAF} 1}$ specific antibody. The Western blot (Fig. 3) shows that p21 is indeed upregulated in response to UV illumination. $\mathrm{p} 21^{\mathrm{WAF} 1}$ is a $\mathrm{p} 53$ responsive gene, hence we tested the expression of $\mathrm{p} 53$ in response to illumination. The A431 cells express mutated p53 (41), which is not upregulated in response to illumination, whereas Cal-39 cells express wild-type p53, which is upregulated in response to illumination (Fig. 3). Although p53 is mutated in A431 cells, both cell lines show an upregulation of $\mathrm{p} 21^{\mathrm{WAF} 1}$ in response to illumination.

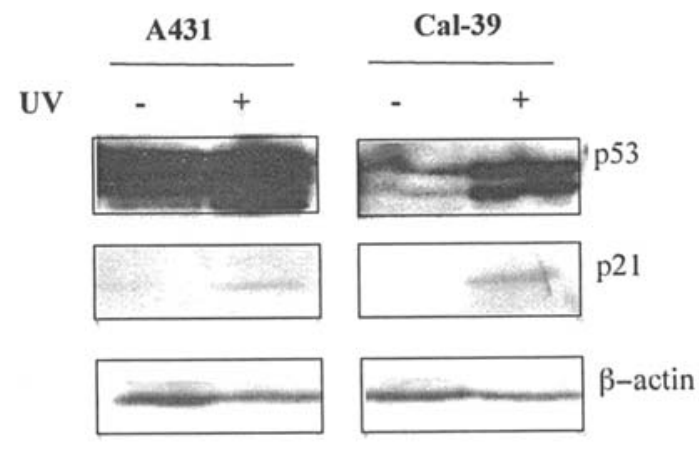

Figure 3. Laser-pulsed UV illumination causes an upregulation of p21 ${ }^{\mathrm{WAF} 1}$ irrespective of the p53 status. Cal-39 and A431 cells were serum-starved prior to illumination. Cell lysate $(75 \mu \mathrm{g})$ was separated by SDS-PAGE and the membrane was probed with a $21^{\mathrm{WAF}}$-specific antibody or an antibody specific against p53. To verify equal loading the membrane was also probed with a specific antibody against $\beta$-actin.

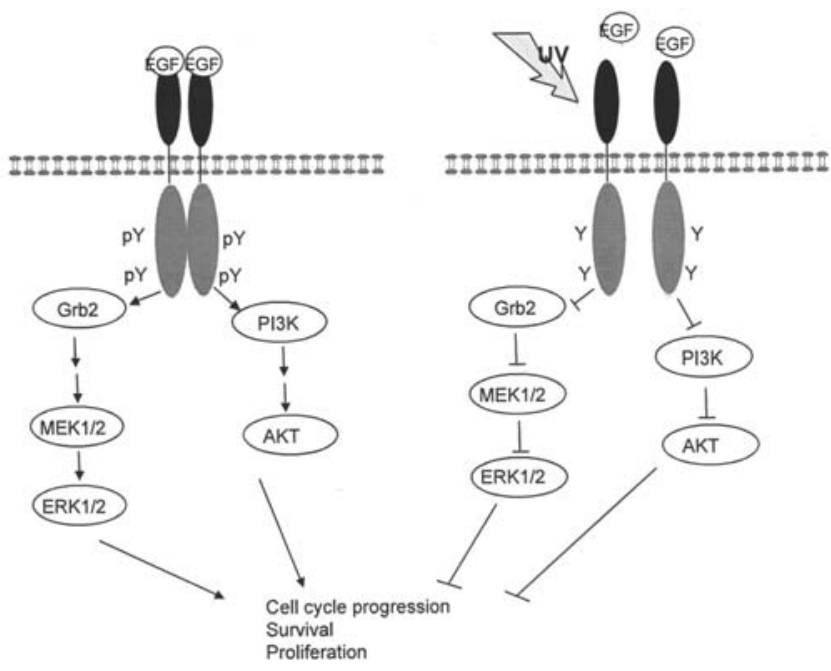

Figure 4. Overview of the cellular pathways affected by the laser-pulsed UV illumination of the EGF receptor leading to attenuation of the EGFR signaling cascade. The figure shows the photoactivation of aromatic residues within the extracellular domain of the EGF receptor, which disrupts the nearby disulphide bridges. This prevents the ligand, i.e. EGF from binding to the receptor and activating the EGFR pathways. In addition it is possible that laser-pulsed UV illumination targets the intracellular domain of the EGF receptor causing photodegradation of phosphorylation-targeted tyrosine residues again preventing the adaptor proteins from binding to the phosphorylated tyrosine residues.

\section{Discussion}

The ErbB family of receptor tyrosine kinases are often found overexpressed in different tumor types, and the overexpression of the receptors is thought to play a role in the pathogenesis of cancer, hence targeting the family members including the EGF receptor is used in cancer therapy. Targeting includes monoclonal antibodies directed against the external moiety of the EGF receptor, which prevents ligand binding and small molecules, which interfere with the intracellular part of the receptor molecule, i.e. its tyrosine kinase activity (42). Herein we describe a new way of inhibiting the EGF receptor using laser-pulsed UV illumination. Laserpulsed UV illumination targets excitation of aromatic amino 
acid residues, leading to disruption of proximal disulphide bridges (25-28). Interestingly, the EGF receptor contains the spatial proximity between disulphide bridges and aromatic residues and in the case of the EGF receptor this disruption prevents downstream signaling from the EGF receptor. As proposed in Fig. 4, the blockage could be through disruption of S-S bridges in the extracellular domain causing the 3dimensional structure of the receptor to be altered, preventing the binding of ligand. In addition the intracellular domain of the EGF receptor contains a high number of aromatic residues including the phosphorylation-targeted tyrosine residues, thus it is also possible that laser-pulsed UV illumination affects the intracellular tyrosines hence preventing downstream signaling.

Fig. 1 shows that an illumination time/power threshold exists above which laser-pulsed UV light can halt EGFR signaling cascades. Blockage of EGFR signaling is not possible below that threshold. This observation is correlated with the fact that above a certain power/illumination time threshold, proteins lose their native 3D structure and functionality. Importantly, the S-S disruption is a reversible process at low power/illumination times.

We describe the attenuation of EGFR signaling as detected by the phosphorylation status of key downstream molecules i.e. AKT and the mitogen activated protein kinases ERK1 and 2. In response to laser-pulsed UV illumination phosphorylation of AKT and ERK1/2 is not detectable upon activation with EGF.

Several reports exist, describing how UV light can activate the EGF receptor hence activating the AKT and MAPK pathway (43-50); this is thought to be mediated through: i) increased expression of EGFR ligands $(51,52)$ and ii) inactivation of receptor-associated phosphatases and iii) altered internalization and degradation $(44,45,53)$. These observations are in contrast to our results. The reason for this discrepancy could be found in the illumination power per unit of illuminated area (fluency). In our experiments the total integrated power over a second is significantly less than the average solar UV output but comparing the actual output during a pulse event we have 1000-fold higher intensity during the pulse event.

Similarly to the results obtained here concerning the upregulation of $\mathrm{p} 21^{\mathrm{WAF} 1}$ in response to illumination are results in different tumor cell lines treated with inhibitors of the EGF receptor. Blockage of the EGF receptor by treating with the inhibitor Gefitinib (Iressa), leads to an upregulation of p $21^{\text {WAF1 }}$ mRNA in a bladder adenocarcinoma cell line (36) and an upregulation of $\mathrm{p} 21^{\mathrm{WAF} 1}$ protein in human head and neck squamous carcinoma cell lines $(39,40)$. Furthermore, an upregulation of $\mathrm{p} 21^{\mathrm{WAF} 1}$ at the protein level was observed in cervical and oral tumor cells treated with Epigallocatechin-3gallate which inhibits the EGFR signaling pathways $(37,38)$ and an upregulation in esophagel cancer cell lines treated with the receptor tyrosine kinase inhibitor erlonitib have been reported (54).

The upregulation of $\mathrm{p} 21^{\mathrm{WAF} 1}$, a $\mathrm{p} 53$ responsive gene was independent of the p53 status, consistent with findings that $\mathrm{p} 21^{\mathrm{WAF} 1}$ can be induced through $\mathrm{p} 53$-dependent as well as p53-independent mechanisms (55-57).

Given the upregulation of $\mathrm{p} 21^{\mathrm{WAF} 1}$, which is a cyclindependent kinase inhibitor, we must assume that laser-pulsed
UV illumination causes the cells to arrest the cell cycle in G1 phase (58), which would be beneficial in inhibiting the proliferative potential of EGFR overexpressing cells.

\section{Acknowledgements}

This research work was supported by the Danish Cancer Society, grant no. 002521109210 and the Natural Science Foundation, grant no. 21-04-0517 to OGI. M.T.N.P. acknowledges the support from Novi Invest and Licfond.

\section{References}

1. Riese DJ and Stern DF: Specificity within the EGF family/ErbB receptor family signaling network. Bioessays 20: 41-48, 1998.

2. Yarden Y and Sliwkowski MX: Untangling the ErbB signalling network. Nat Rev Mol Cell Biol 2: 127-137, 2001.

3. Olayioye MA, Neve RM, Lane HA and Hynes NE: The ErbB signaling network: receptor heterodimerization in development and cancer. EMBO J 19: 3159-3167, 2000.

4. Casanova ML, Larcher F, Casanova B, et al: A critical role for ras-mediated, epidermal growth factor receptor-dependent angiogenesis in mouse skin carcinogenesis. Cancer Res 62: 3402-3407, 2002.

5. Kiguchi K, Beltran L, Rupp T and Di Giovanni J: Altered expression of epidermal growth factor receptor ligands in tumor promoter-treated mouse epidermis and in primary mouse skin tumors induced by an initiation-promotion protocol. Mol Carcinog 22: $73-83,1998$.

6. Sibilia M, Fleischmann A, Behrens A, et al: The EGF receptor provides an essential survival signal for SOS-dependent skin tumor development. Cell 102: 211-220, 2001.

7. Segrelles C, Ruiz S, Perez P, et al: Functional roles of Akt signaling in mouse skin tumorigenesis. Oncogene 21: 53-64, 2002.

8. Budiyanto A, Bito T, Kunisada M, Ashida M, Ichihashi M and Ueda M: Inhibition of the epidermal growth factor receptor suppresses telomerase activity in HSC-1 human cutaneous squamous cell carcinoma cells. J Invest Dermatol 121: 1088-1094, 2003.

9. Kim YN, Dam P and Bertics PJ: Caveolin-1 phosphorylation in human squamous and epidermoid carcinoma cells: dependence on ErbB1 expression and Src activation. Exp Cell Res 280: 134-147, 2002.

10. Mendelsohn $\mathrm{J}$ and Baselga $\mathrm{J}$ : The EGF receptor family as targets for cancer therapy. Oncogene 19: 6550-6565, 2000.

11. Woodburn JR: The epidermal growth factor receptor and its inhibition in cancer therapy. Pharmacol Ther 82: 241-250, 1999.

12. Yarden Y: The EGFR family and its ligands in human cancer. signalling mechanisms and therapeutic opportunities. Eur $\mathbf{J}$ Cancer 37: 3-8, 2001.

13. Arteaga CL: The epidermal growth factor receptor: from mutant oncogene in non-human cancers to therapeutic target in human neoplasia. J Clin Oncol 19: 32-40, 2001.

14. Sparrow LE and Heenan PJ: Differential expression of epidermal growth factor receptor in melanocytic tumours demonstrated by immunohistochemistry and mRNA in situ hybridization. Australas J Dermatol 40: 19-24, 1999.

15. Gordon-Thomson C, Mason RS and Moore GP: Regulation of epidermal growth factor receptor expression in human melanocytes. Exp Dermatol 10: 321-328, 2001.

16. Udart M, Utikal J, Krahn GM and Peter RU: Chromosome 7 aneusomy. A marker for metastatic melanoma? Expression of the epidermal growth factor receptor gene and chromosome 7 aneusomy in nevi, primary malignant melanomas and metastases. Neoplasia 3: 245-254, 2001.

17. Polsky D and Cordon-Cardo C: Oncogenes in melanoma. Oncogene 22: 3087-3091, 2003.

18. Hunts J, Ueda M, Ozawa S, Abe O, Pastan I and Shimizu N: Hyperproduction and gene amplification of the epidermal growth factor receptor in squamous cell carcinomas. Jpn J Cancer Res 76: 663-666, 1985.

19. Rho O, Beltran LM, Gimenez-Conti IB and Di Giovanni J: Altered expression of the epidermal growth factor receptor and transforming growth factor-alpha during multistage skin carcinogenesis in SENCAR mice. Mol Carcinog 11: 19-28, 1994. 
20. El-Abaseri TB, Fuhrman J, Trempus C, Shendrik I, Tennant RW and Hansen LA: Chemoprevention of UV light-induced skin tumorigenesis by inhibition of the epidermal growth factor receptor. Cancer Res 65: 3958-3965, 2005.

21. Hansen LA, Woodson RL II, Holbus S, Strain K, Lo YC and Yuspa SH: The epidermal growth factor receptor is required to maintain the proliferative population in the basal compartment of epidermal tumors. Cancer Res 60: 3328-3332, 2001.

22. Baselga $J$ and Arteaga CL: Critical update and emerging trends in epidermal growth factor receptor targeting in cancer. J Clin Oncol 23: 2445-2459, 2005.

23. Ioerger TR, Du C and Linthicum DS: Conservation of cys-cys trp structural triads and their geometry in the protein domains of immunoglobulin superfamily members. Mol Immunol 36: 373-386, 1999

24. Petersen MTN, Jonson PH and Petersen SB: Amino acid neighbours and detailed conformational analysis of cysteines in proteins. Protein Eng 12: 535-548, 1999.

25. Prompers JJ, Hilbers CW and Perpermans HAM: Tryptophan mediated photoreduction of disulfide bonds causes unusual fluorescence behaviour of Fusarium solani pisi cutinase. FEBS Lett 45: 409-416, 1999.

26. Neves-Petersen MT, Gryczynski Z, Lakowicz J, Fojan P, Pedersen S, Petersen E and Petersen SB: High probability of disrupting a disulphide bridge mediated by an endogenous excited tryptophan residue. Protein Sci 11: 588-600, 2002.

27. Vanhooren A, Devreese B, Vanhee K, van Beeumen J and Hanssens IA: Photoexcitation of tryptophan groups induces reduction of two disulfide bridges in goat a-lactalbumin. Biochemistry 41: 11035-11043, 2002.

28. Neves-Petersen MT, Snabe T, Klitgaard S, Duroux M and Petersen SB: Photonic activation of disulfide bridges achieves oriented protein immobilization on biosensor surfaces. Protein Sci 15: 343-351, 2006

29. Groves RW, Allen MH and MacDonald DM: Abnormal expression of epidermal growth factor receptor in cutaneous epithelial tumours. J Cutan Pathol 19: 66-72, 1992.

30. Berchuck A, Rodriguez G, Kamel A, Soper JT, Clarke-Pearson DL and Bast RC: Expression of epidermal growth factor receptor and HER-2/neu in normal and neoplastic cervix, vulva, and vagina. Obstet Gynecol 76: 381-387, 1990.

31. Wu X, Xin Y, Yao J, Hasui K, Tsuyama S, Yonezawa S and Murata F: Expression of epithelial growth factor receptor and its two ligands, transforming growth factor-alpha and epithelial growth factor, in normal and neoplastic squamous cells in the vulva: an immunohistochemical study. Med Electron Microsc 34: 179-184, 2001

32. Zorzou MP, Stratigos A, Efstathiou E and Bamias A: Exacerbation of psoriasis after treatment with an EGFR tyrosine kinase inhibitor. Acta Derm Venereol 84: 308-309, 2004.

33. Varani J, Lateef H, Fay K and Elder JT: Antagonism of epidermal growth factor receptor tyrosine kinase ameliorates the psoriatic phenotype in organ-cultured skin. Skin Pharmacol Physiol 18: 123-131, 2005.

34. Bradford MM: A rapid and sensitive method for the quantitation of microgram quantities of protein utilizing the principle of protein-dye binding. Anal Biochem 72: 248-254, 1976.

35. Krupp MN, Connolly DT and Lane MD: Synthesis, turnover, and down-regulation of epidermal growth factor receptors in human A431 epidermoid carcinoma cells and skin fibroblasts. J Biol Chem 257: 11489-11496, 1982.

36. Ariyama H, Qin B, Baba E, Tanaka R, Mitsugi K, Harada M and Nakano S: Gefitinib, a selective EGFR tyrosine kinase inhibitor, induces apoptosis through activation of Bax in human gallbladder adenocarcinoma cells. J Cell Biochem 97: 724-734, 2006.

37. Sah JF, Balasubramanian S, Eckert RL and Rorke EA: Epigallocatechin-3-gallate inhibits epidermal growth factor receptor signaling pathway. Evidence for direct inhibition of ERK1/2 and AKT kinases. J Biol Chem 279: 12755-12762, 2004.

38. Hsu CH, Gao M, Chen CL, Yeh PY and Cheng AL: Inhibitors of epidermoid growth factor receptor suppress cell growth and enhance chemosensitivity of nasopharyngeal cancer cells in vitro. Oncology 68: 538-547, 2005.
39. Di Gennaro E, Barbarino M, Bruzzese F, et al: Critical role of both $\mathrm{p} 27 \mathrm{KIP} 1$ and $\mathrm{p} 21 \mathrm{CIP} 1 / \mathrm{WAF} 1$ in the antiproliferative effect of ZD1839 ('Iressa'), an epidermal growth factor receptor tyrosine kinase inhibitor, in head and neck squamous carcinoma cells. J Cell Physiol 195: 139-150, 2003.

40. Magne N, Fischel JL, Tiffon C, et al: Molecular mechanisms underlying the interaction between ZD1839 ('Iressa') and cisplatin/5-fluorouracil. Br J Cancer 89: 585-592, 2003.

41. Reiss M, Brash DE, Munoz-Antonia T, Simon JA, Ziegler A, Vellucci VF and Zhou ZL: Status of the p53 tumor suppressor gene in human squamous carcinoma cell lines. Oncol Res 4: 349-357, 1992.

42. Bianco R, Melisi D, Ciardiello F and Tortora G: Key cancer cell signal transduction pathways as therapeutic targets. Eur J Cancer 42: 290-294, 2006.

43. Matsumura Y and Ananthaswamy HN: Toxic effects of ultraviolet radiation on the skin. Toxicol Appl Pharmacol 195: 298-308, 2004.

44. Huang RP, Wu JX, Fan Y and Adamson ED: UV activates growth factor receptors via reactive oxygen intermediates. J Cell Biol 133: 211-220, 1996.

45. Coffer PJ, Burgering BM, Peppelenbosch MP, Bos JL and Kruijer W: UV activation of receptor tyrosine kinase activity. Oncogene 11: 561-569, 1995.

46. Iordanov MS, Choi RJ, Ryabinina OP, Dinh TH, Bright RK and Magun BE: The UV (Ribotoxic) stress response of human keratinocytes involves the unexpected uncoupling of the Rasextracellular signal-regulated kinase signaling cascade from the activated epidermal growth factor receptor. Mol Cell Biol 22: 5380-5394, 2002.

47. Katiyar SK: A single physiologic dose of ultraviolet light exposure to human skin in vivo induces phosphorylation of epidermal growth factor receptor. Int J Oncol 19: 459-464, 2001.

48. Wan YS, Wang ZQ, Shao Y, Voorhees JJ and Fisher GJ: Ultraviolet irradiation activates PI 3-kinase/AKT survival pathway via EGF receptors in human skin in vivo. Int J Oncol 18: 461-466, 2001.

49. Warmuth I, Harth Y, Matsui MS, Wang N and De Leo VA: Ultraviolet radiation induces phosphorylation of the epidermal growth factor receptor. Cancer Res 54: 374-376, 1994.

50. El-Abaseri TB, Putta S and Hansen LA: Ultraviolet irradiation induces keratinocyte proliferation and epidermal hyperplasia through the activation of the epidermal growth factor receptor. Carcinogenesis 27: 225-231, 2006

51. Brown NA, Compton LA and Clinton GM: Antibodies against highly conserved sites in the epidermal growth factor receptor tyrosine kinase domain as probes for structure and function. Biochemistry 32: 4659-4664, 1993.

52. Ellem KA, Cullinan M, Baumann KC and Dunstan A: UVR induction of TGF alpha: a possible autocrine mechanism for the epidermal melanocytic response and for promotion of epidermal carcinogenesis. Carcinogenesis 9: 797-801, 1988.

53. Ley KD, Ellem KA: UVC modulation of epidermal growth factor receptor number in HeLa S3 cells. Carcinogenesis 13: 183-187, 1992.

54. Sutter AP, Hopfner M, Huether A, Maaser K and Scherubl H: Targeting the epidermal growth factor receptor by erlotinib (Tarceva) for the treatment of esophageal cancer. Int J Cancer 118: 1814-1822, 2006.

55. Michieli P, Chedid M, Lin D, Pierce JH, Mercer WE and Givol D: Induction of WAF1/CIP1 by a p53-independent pathway. Cancer Res 54: 3391-3399, 1994.

56. Haapajarvi T, Kivinen L, Heiskanen A, Des Bordes C, Datto MB, Wang XF and Laiho M: UV radiation is a transcriptional inducer of p21(Cip1/Waf1) cyclin-kinase inhibitor in a p53-independent manner. Exp Cell Res 248: 272-279, 1999.

57. Huang F, Kirkpatrick D, Jiang X, Gygi S and Sorkin A: Differential regulation of EGF receptor internalization and degradation by multiubiquitination within the kinase domain. Mol Cell 21: 737-748, 2006.

58. Sherr CJ and Roberts JM: CDK inhibitors: positive and negative regulators of G1-phase progression. Genes Dev 13: 1501-1512, 1999. 